\title{
ॠUSGS
}

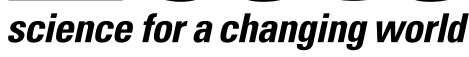

\section{Volcano and Earthquake Monitoring Plan for the Yellowstone Volcano Observatory, 2006-2015}

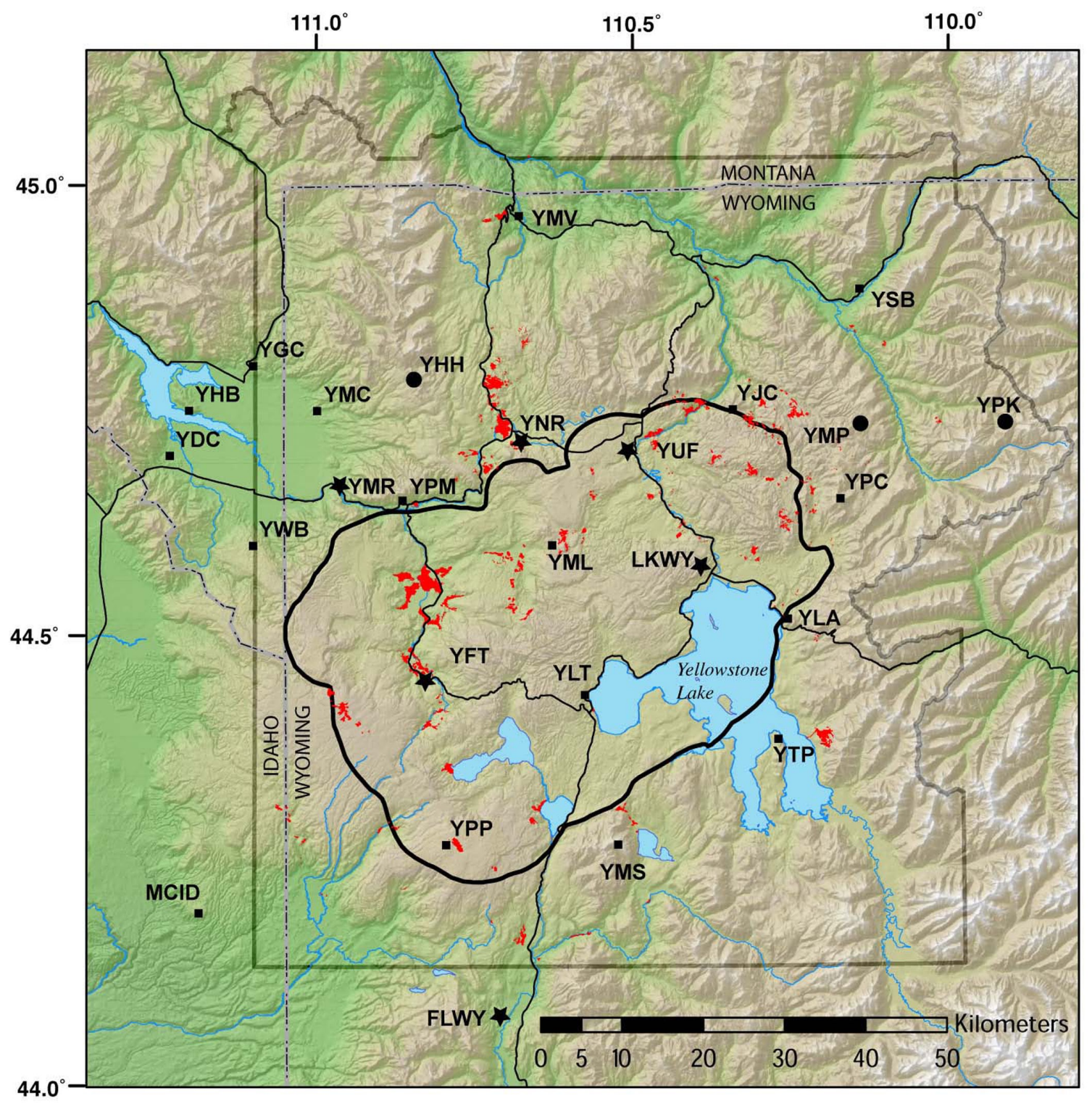

Scientific Investigation Report 2006-5276

U.S. Department of the Interior U.S. Geological Survey 


\section{Volcano and Earthquake Monitoring Plan for the Yellowstone Volcano Observatory, 2006-2015}

By the Yellowstone Volcano Observatory

Scientific Investigations Report 2006-5276

U.S. Department of the Interior

U.S. Geological Survey 


\title{
U.S. Department of the Interior DIRK KEMPTHORNE, Secretary
}

\section{U.S. Geological Survey Mark D. Myers, Director}

\section{U.S. Geological Survey, Reston, Virginia: 2006}

This report and any updates to it are available online at: http://pubs.usgs.gov/sir/2006/5276/

\author{
For product and ordering information: \\ Telephone: 1-888-ASK-USGS \\ For more information contact: \\ Yellowstone Volcano Observatory \\ Mail Stop 910 \\ U.S.Geological Survey \\ 345 Middlefield Road \\ Menlo Park, CA 94025 \\ http://volcanoes.usgs.gov/yvo/
}

World Wide Web: http//www.usgs.gov/pubprod

Any use of trade, product, or firm names in this publication is for descriptive purposes only and does not imply endorsement of the U.S. Government.

Produced in the Western Region, Menlo Park, California

Manuscript approved for publication, October 18, 2006

Text edited by Peter $\mathrm{H}$. Stauffer

Layout and design by Judy Weathers

FRONT COVER

The graphic shows the seismic network of Yellowstone National Park. Small black squares and associated letter codes are one-component stations, large dots are three-component stations, and stars are broadband stations. The FLWY station is maintained by the USGS/ANSS. Thick black line is the boundary of the Yellowstone Caldera. Thin black lines are roads. Gray outline is park boundary. Red regions are thermal areas. 


\section{Contents}

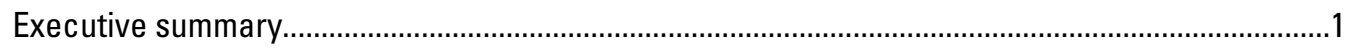

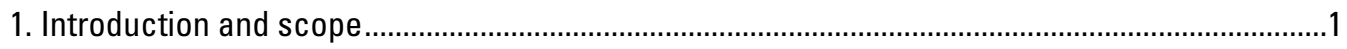

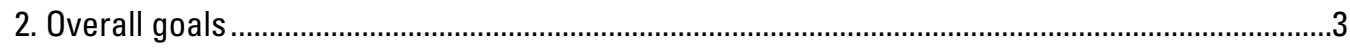

3. Current status of the Volcano and Earthquake Monitoring System..............................................

3a. Seismic network ........................................................................................................

3b. Ground-deformation network ...........................................................................................

3c. Gas, water, and thermal monitoring ............................................................................

4. Anticipated future volcano and earthquake monitoring needs for the Yellowstone volcanic field —a 10-year view .........................................................................................

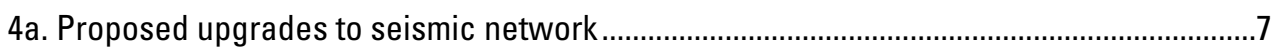

4b. Proposed upgrades to geodetic network ......................................................................

4c. Proposed upgrades to gas, water, and thermal monitoring network ...................................

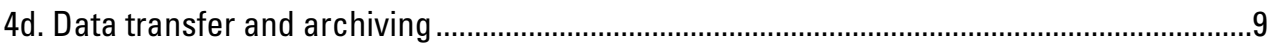

4e. Nonpermanent monitoring (temporary experiments) .....................................................

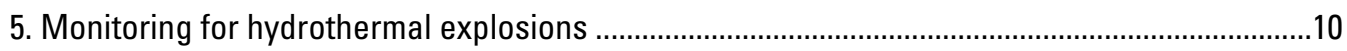

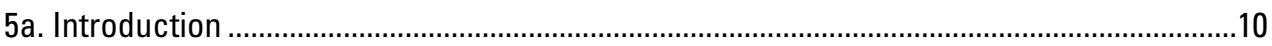

5 b. Proposed instrumentation for a hydrothermal monitoring network ...................................10

6. Summary

Appendix 1. Locations and names of monitoring stations .........................................................12

\section{Figures}

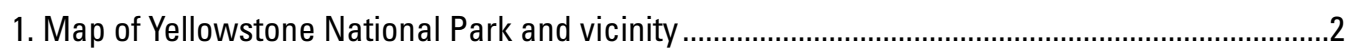

2. Map showing seismic network of Yellowstone National Park .....................................................

3. Map showing GPS network of Yellowstone National Park ......................................................6

4. Map showing stream gages of Yellowstone National Park .............................................................7

5. Map showing proposed new instruments to be added to the backbone volcano-monitoring network.................................................................................................

6. Map showing potential hydrothermal monitoring network for Norris Geyser Basin ...................11 


\title{
Volcano and Earthquake Monitoring Plan for the Yellowstone Volcano Observatory, 2006-2015
}

\author{
By the Yellowstone Volcano Observatory'
}

\section{Executive Summary}

To provide Yellowstone National Park (YNP) and its surrounding communities with a modern, comprehensive system for volcano and earthquake monitoring, the Yellowstone Volcano Observatory (YVO) has developed a monitoring plan for the period 2006-2015. Such a plan is needed so that YVO can provide timely information during seismic, volcanic, and hydrothermal crises and can anticipate hazardous events before they occur. The monitoring network will also provide high-quality data for scientific study and interpretation of one of the largest active volcanic systems in the world. Among the needs of the observatory are to upgrade its seismograph network to modern standards and to add five new seismograph stations in areas of the park that currently lack adequate station density. In cooperation with the National Science Foundation (NSF) and its Plate Boundary Observatory Program (PBO), YVO seeks to install five borehole strainmeters and two tiltmeters to measure crustal movements. The boreholes would be located in developed areas close to existing infrastructure and away from sensitive geothermal features. In conjunction with the park's geothermal monitoring program, installation of new stream gages, and gas-measuring instruments will allow YVO to compare geophysical phenomena, such as earthquakes and ground motions, to hydrothermal events, such as anomalous water and gas discharge. In addition, YVO seeks to characterize the behavior of geyser basins, both to detect any precursors to hydrothermal explosions and to monitor earthquakes related to fluid movements that are difficult to detect with the current monitoring system. Finally, a monitoring network consists not solely of instruments, but requires also a secure system for real-time transmission of data. The current telemetry system is vulnerable to failures that could jeopardize data transmission out of Yellowstone. Future advances in monitoring technologies must be accompanied by improvements in

\footnotetext{
${ }^{1}$ Attendees at the planning meeting and contributors to this publication include Jacob B. Lowenstern, Henry Heasler, Robert B. Smith, W. Arabasz, D. Bergfeld, S. Borenstein, R. Burcalu, P. Cervelli, W. Chang, B. Chouet, D. Drobeck, D. Dzurisin, W. Evans, J. Ewert, J. Farrell, K. Feaux, R. Fournier, C. Gardner, M. Guffanti, D. Hill, S. Hurwitz, C. Jaworowski, K. McGee, A. Moeinvaziri, L. Morgan, T. Murray, M. Nathenson, T. Olliff, D. Oppenheimer, C. Pankow, C. Puskas, J. Quick, D. Susong, G. Waite, and J. Wynn. J. Power and J. Dixon reviewed this plan.
}

the infrastructure for data transmission. Overall, our strategy is to (1) maximize our ability to provide rapid assessments of changing conditions to ensure public safety, (2) minimize environmental and visual impact, and (3) install instrumentation in developed areas.

\section{Introduction and Scope}

In 2001, the U.S. Geological Survey (USGS) joined forces with Yellowstone National Park (YNP) and the University of Utah to form the Yellowstone Volcano Observatory (YVO). This organization builds upon a 40year program of geologic monitoring and related research at Yellowstone by the USGS and the University of Utah. YVO provides the park with critical capabilities, acting as a partner that can operate modern monitoring facilities, has the expertise to scrutinize seismic and ground deformation signals, and can rapidly assess the significance of geologic processes that may threaten visitors to Yellowstone. YVO gives the park the capability to respond rapidly to geologic hazards and a mechanism for answering requests for information from park management, civil-defense authorities, the media, and the public. For YVO to fulfill its promise it must continue to build a modern, robust, and reliable monitoring system that provides effective and unobtrusive security for the park and its visitors.

Forty years of modern geologic research demonstrate the need for vigilant monitoring to observe and interpret signals from the Earth and to anticipate hazardous geologic events before they occur. In the past two million years, Yellowstone (fig. 1) has produced three of the largest volcanic eruptions on Earth. Debris from those events spread over much of the western and central United States. Since the last such eruption, 640,000 years ago, immense but relatively nonexplosive lava flows have filled the Yellowstone caldera. The hydrothermal system that fuels the park's geysers can produce violent explosions, as it has numerous times in the past 15,000 years. Pocket Basin, Mary Bay, Turbid Lake, and Indian Pond all owe their origins to catastrophic boiling of shallow ground water, causing upheaval and ejection of megatons of rocks and debris. Thousands of earthquakes occur each year at Yellowstone. In 1959, the magnitude 7.5 Hebgen Lake earthquake, the largest historical earthquake in the 
interior of the western United States, killed 28 people, caused millions of dollars in damage in the park and nearby towns, and dramatically changed many of the hydrothermal features.

All of the above geologic events can occur again at Yellowstone, and some likely will within the coming decades. A recent volcano hazards assessment by the USGS identified Yellowstone as a high-threat volcanic system with a monitoring system that is not commensurate with the potential volcanic threat (report available at http://pubs.usgs.gov/of/2005/1164/). Similar volcanic systems, such as Long Valley Caldera (California) and Campi Flegrei (Italy), pose similar hazards but are monitored by more modern and complete monitoring systems. Those systems provide society with insights into the dynamics of magma bodies like that beneath Yellowstone. The monitoring system at Yellowstone can and should be upgraded to detect the subtle precursory changes that are likely to occur before hazardous events so that there can be adequate advance notice to the park and the surrounding communities.

On November 9 and 10, 2005, YVO convened a special planning meeting to define a series of goals that would ensure that Yellowstone, its visitors, and neighboring communities are protected by a modern earthquake and volcano monitoring system. This document summarizes the results of the meeting, including monitoring goals and the equipment needed to attain them. Though cost or environmental constraints may preclude full implementation of the plan, it is nonetheless important to communicate the limitations of the current monitoring system and the identified avenues for improvement.

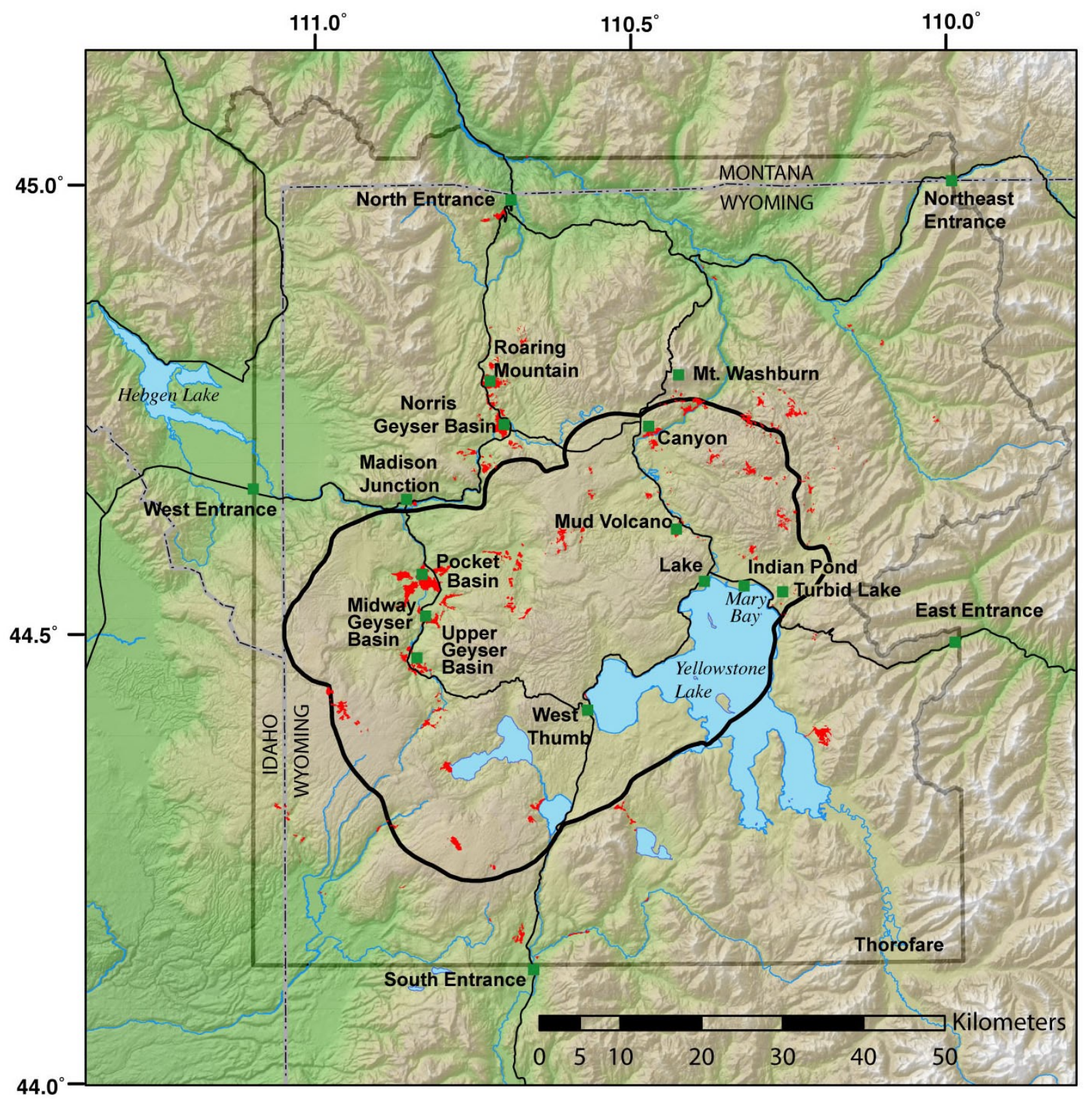

Figure 1. Map of Yellowstone National Park and vicinity. Thick black line is the boundary of the Yellowstone Caldera. Thin black lines are roads. Gray outline is park boundary. Red regions are thermal areas. Dashed line shows state boundaries. 


\section{Overall Goals}

The Yellowstone volcano and earthquake monitoring system should:

a. Detect earth signals that indicate changes in the magmatic system that underlies Yellowstone. These signals include earthquakes, deforming ground, and increased heat, gas, or water flow.

b. Provide rapid notification to park and local authorities in the surrounding region about the location of damaging earthquakes, their magnitudes, and the likely extent of damage at different locations within the region.

c. Include the capability to monitor thermal basins so that we may detect precursors to hydrothermal explosions, which are a major long-term hazard within the park.

d. Enable the assessment of earthquake and volcanic hazards so that their impacts can be mitigated.

\section{Current Status of the Volcano and Earthquake Monitoring System}

Volcanologists have three principal methods for assessing volcanic activity. They evaluate the types, magnitudes, and locations of earthquakes; they observe and interpret uplift and subsidence of the ground surface; and they detect changes in the discharge of heat, water, and gases from volcanic terrain. All of these signals, plus others, are used together to assess developments at a volcano. The Yellowstone volcanic system has the additional characteristic that it is impacted by large earthquakes that occur as part of the mountain-building processes in the western United States. Therefore, the YVO monitoring network should also be able to rapidly characterize the amount of ground movement (and damage) from large regional earthquakes. The following sections provide a summary of the current monitoring system and its capabilities and weaknesses.

\section{3a. Seismic Network}

Currently, the University of Utah Seismographic Stations (UUSS) operates the Yellowstone seismographic network, with one additional station maintained by the USGS and its Advanced National Seismic System (ANSS). Most of the funding for the YVO network comes from the USGS, with some additional support through YNP and the National Science Foundation (NSF). There are three types of seismograph stations in the network. Single-component stations measure short-period $(1-10 \mathrm{~Hz})$ vertical ground motion but do not measure lateral movement; three-component stations yield data from both horizontal and vertical motions; broadband seismic stations are a type of three-component station that detects short-period energy as well as much longer waves that range over periods from one second to hundreds of seconds. The YVO network (fig. 2) consists of 26 seismograph stations, including 6 modern broadband stations, 3 three-component stations, and 17 older single-component stations. Of the 26 seismometers, 20 are within the boundaries of Yellowstone National Park. The data are available in real time through the UUSS and YVO websites (http://www.seis.utah.edu/ and http://volcanoes.usgs.gov/yvo/.

When ground motions are intense, such as during a large earthquake, none of these systems can faithfully record the amount of shaking. Earthquake magnitudes can still be determined through use of distant seismograph stations, but the local effects, detailed locations, and ground accelerations of the earthquake cannot be accurately estimated. To address this need, seismologists co-locate accelerometers with broadband seismometers. These instruments record an additional three channels of ground-acceleration data that maintain the fidelity of signal size with large earthquakes. Seismic networks with accelerometers can determine the intensity of local shaking. If there were multiple accelerometers at Yellowstone, the UUSS could produce a ShakeMap within seconds of an earthquake and make it available to emergency managers, enabling them in to predict locations that have suffered the most damage and to deploy emergency-response resources appropriately. Currently, however, there are no accelerometers deployed at Yellowstone.

One of the key elements of successful volcano monitoring is calculating both the location and depth of the small earthquakes that can accompany ascent of magma through the crust. A rule of thumb is that instrument spacing for this purpose should be no more than twice the depth of the earthquake. In other words, to reliably estimate the depth of an earthquake at $2 \mathrm{~km}$, one would need station spacing of less than $4 \mathrm{~km}$. For Yellowstone, that would require a $25 \times 25$ grid of seismic stations, or 625 seismometers! Clearly, this is not feasible from an environmental, economic, or personnel standpoint, but it points out the challenge in monitoring a volcano as large as Yellowstone. The actual spacing of seismic stations within the park averages about $18 \mathrm{~km}$. Stations are more narrowly spaced in northwest portions of the park and are sparser in other regions.

All YVO seismometers are located at the ground surface. Modern seismic networks often include several downhole seismometers, instruments placed in boreholes to avoid environmental noise such as wind, traffic, and other signals present at the Earth's surface.

Because of the reduction of noise, such instruments provide highly improved data relative to surface instruments and can detect much smaller earthquakes.

A final consideration is that detection of some types of volcanic earthquakes requires modern equipment now only partially implemented at Yellowstone. Movement of volcanic fluids (magma and hot water and gas) can cause long-wavelength vibrations that are best detected with the newer broadband technology. Though we have not recorded any long-period earthquakes in Yellowstone, they may still be occurring, as we may not have the proper instrumentation to detect them. 


\section{3b. Ground-Deformation Network}

Ground deformation at Yellowstone is currently monitored through four principle techniques:

1. Continuous global positioning system (GPS), a satellite-based technique that provides frequent (daily or hourly) high-precision locations of individual receivers placed on monuments within the park (fig. 3); data are telemetered daily to YVO. This technique is critical for volcano monitoring because it yields high temporal resolution (frequent updates) and can therefore alert scientists to rapid ground movements that may accompany subterranean magma movement.

2. Interferometric synthetic aperture radar (InSAR), a satellite-based technique that provides one to two synoptic views per year of ground movement over the entire park. InSAR data are best collected during the summer months because the technique does not penetrate snow cover, which prevents reproducible measurement of changes in the elevation of the ground surface.

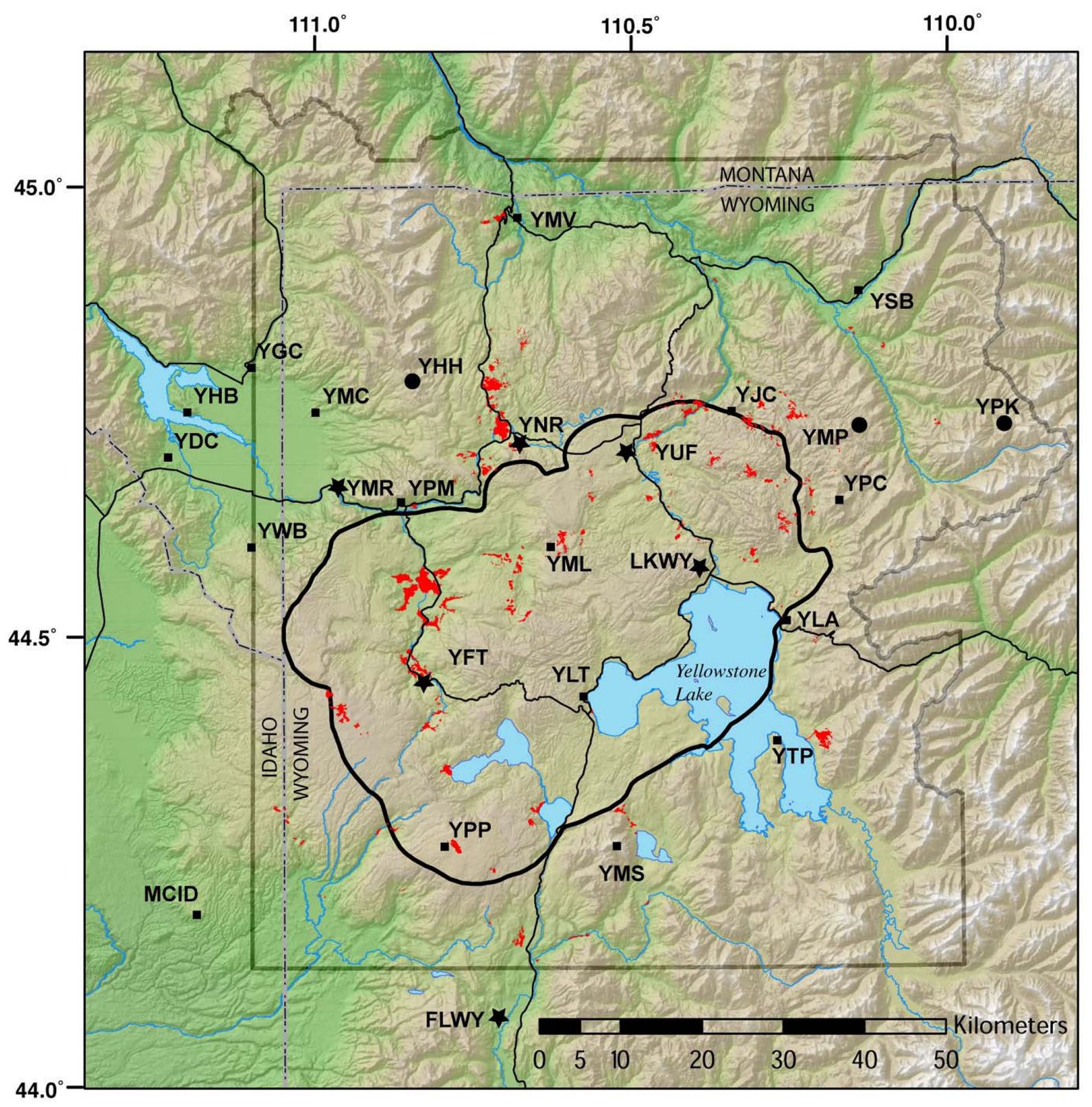

Figure 2. Seismic network of Yellowstone National Park. Small black squares and associated letter codes are onecomponent stations, large dots are three-component stations, and stars are broadband stations. The FLWY station is maintained by the USGS/ANSS. Thick black line is the boundary of the Yellowstone Caldera. Thin black lines are roads. Gray outline is park boundary. Red regions are thermal areas. 
3. Campaign GPS surveys, in which GPS data are collected at many stations on an annual or less frequent basis using temporary deployments of GPS receivers. This increases the spatial coverage for which GPS data are available and provides more regional information than leveling.

4. Precise leveling that measures the vertical component of ground motion through labor-intensive surveying.

The technique yields an annual or less frequent, highprecision determination of ground movement over one or more surveyed traverses.

InSAR data are processed annually by YVO staff and colleagues. Other YVO staff continue periodic leveling and GPS campaigns. Currently, the only permanent equipment required for techniques 3 and 4 are the small brass benchmarks, often located along roads, which serve as the points for comparison of ground movement.

YVO, through the University of Utah, operates six continuous GPS stations at Yellowstone. Recently, the National Science Foundation (NSF), through its EarthScope program and with help from the University of Utah, installed six new GPS stations on the ground as part of their Plate Boundary Observatory (PBO) project, bringing the total number of GPS stations at Yellowstone to 12. PBO has funding for three more GPS stations within the park and eight additional stations in areas surrounding the park. These new stations will add critical information to the YVO monitoring database. All of the GPS data are available in near-real time via the Internet at the UNAVCO data center, a nonprofit company partially funded through NSF.

Other techniques for volcano monitoring include downhole strainmeters and tilt-meters, but these are not currently deployed at Yellowstone. EarthScope's PBO has funding to install five strainmeters at Yellowstone within the next three years (2006-2008). Strainmeters are sensitive instruments that are carefully sealed within drill holes and typically located 300-600 feet beneath the ground surface. They detect very slight rock motions that can correspond to regional tectonic activity, magma intrusion, or groundwater flow. The instruments are so sensitive that they can detect nanostrain events, equivalent to shrinkage or expansion of the United States by the thickness of a poker chip $(0.5 \mathrm{~cm})$. The instruments excel at the detection of transient motion of the Earth at time scales intermediate between that of seismometers and GPS receivers. For example, ground movements with periods of hours to days can easily be seen with strainmeter data. PBO strainmeter installations include three-component seismometers, waterlevel gages, and thermometers as well as the actual strainmeter. As such, they can provide highly improved monitoring capabilities for YVO.

Like a carpenter's level, tiltmeters provide information on very slight changes in slope angle, such as can occur during episodes of ground deformation. Tiltmeters are typically installed in shallow $(\sim 10-30 \mathrm{~m})$ boreholes and are useful when deformation occurs rapidly. Compared with GPS results, which are typically calculated once per day, tilt data provide a continuous stream of data sampled every few seconds. The instruments are relatively inexpensive and easily deployed. In the 1980s (as part of a Ph.D. thesis project) tiltmeters were installed at Yellowstone in five shallow $(30 \mathrm{~m})$ boreholes near park developments. Though the instruments have since been removed, new instruments could be re-deployed in the existing holes. Tiltmeters are not as sensitive as strainmeters, but are simple, reliable, and easy to install.

\section{3c. Gas, Water, and Thermal Monitoring}

Volcanic eruptions are typically preceded by increases in the amount of heat and gases discharged from the Earth above the rising magma. Such changes can occur months, weeks, or only days before an eruption. In some cases, the gas may indicate the presence of new magma that will never reach the surface. Identification of increased discharge of volcanic gases is critical in differentiating regional seismic events from those involving new magma. Another reason to monitor gas concentrations and fluxes is because volcanic and geothermal gases are toxic, and can occasionally accumulate to lethal concentrations at or near the ground surface. Worldwide, there have been thousands of deaths from volcanic gases within the past 30 years, including 1,800 human deaths at Lake Nyos, Cameroon, in 1986. At Yellowstone, although animals occasionally die from toxic-gas inhalation, only one human death (in a construction pit) has been clearly related to toxic gases since the park's founding.

The flow of heat and thermal water are two other parameters that can yield insight into the underlying magma system. By measuring the discharge of groundwater from Yellowstone, and measuring the dissolved components, one can infer the amount of thermal water escaping to the surface. Some scientists have suggested that the flow of thermal water may be linked to uplift/ subsidence cycles of the Yellowstone Caldera and that the deep migration of fluids may actually cause uplift and subsidence.

The following monitoring techniques for gas, water, and heat are currently employed at Yellowstone:

1. Gas: As of May 2006, there are no installed sensors at Yellowstone to measure either the concentration or flux of geothermal gases. The USGS undertakes annual to biennial programs of airborne gas monitoring, in which low-flying airplanes map the concentration of gases within plumes discharged from thermal basins. These flights usually take place for two days, often in the spring. Other research is undertaken by individual researchers with collection permits who sample gases, usually on an annual basis.

2. Water: Eleven stream gages are located within Yellowstone National Park to measure the flow of river water and, in some cases, its temperature (fig. 4). Such information is used by biologists and climatologists as well as geologists. YNP supports the network through its geothermal monitoring 
program. YNP also coordinates a chloride-

flux program that combines the stream-gage measurements with chemical analysis of the waters to determine the amounts of volcanogenic materials dissolved in river waters. There are currently no sensors installed to provide continuous data on any aspect of water chemistry. Other studies of Yellowstone waters are undertaken by individual researchers with collection permits who sample waters, usually on an annual basis.

3. Heat: Heat flow is estimated through the chloride flux program (see discussion above) and through occasional airborne missions equipped with infrared sensors. The YNP geothermal monitoring program has recently initiated annual flights to characterize changes in the heat discharge of thermal basins that could be due to volcanic, tectonic, or human-caused changes. Heat is also estimated at numerous point sources with thermistors linked to field data-loggers that are regularly downloaded by park staff. The data are only retrieved periodically (every few months) but provide useful monitoring of changes in the temperature of pools and in ground temperature. Occasionally, the field loggers fail prior to data downloading, resulting in days or weeks of lost data.

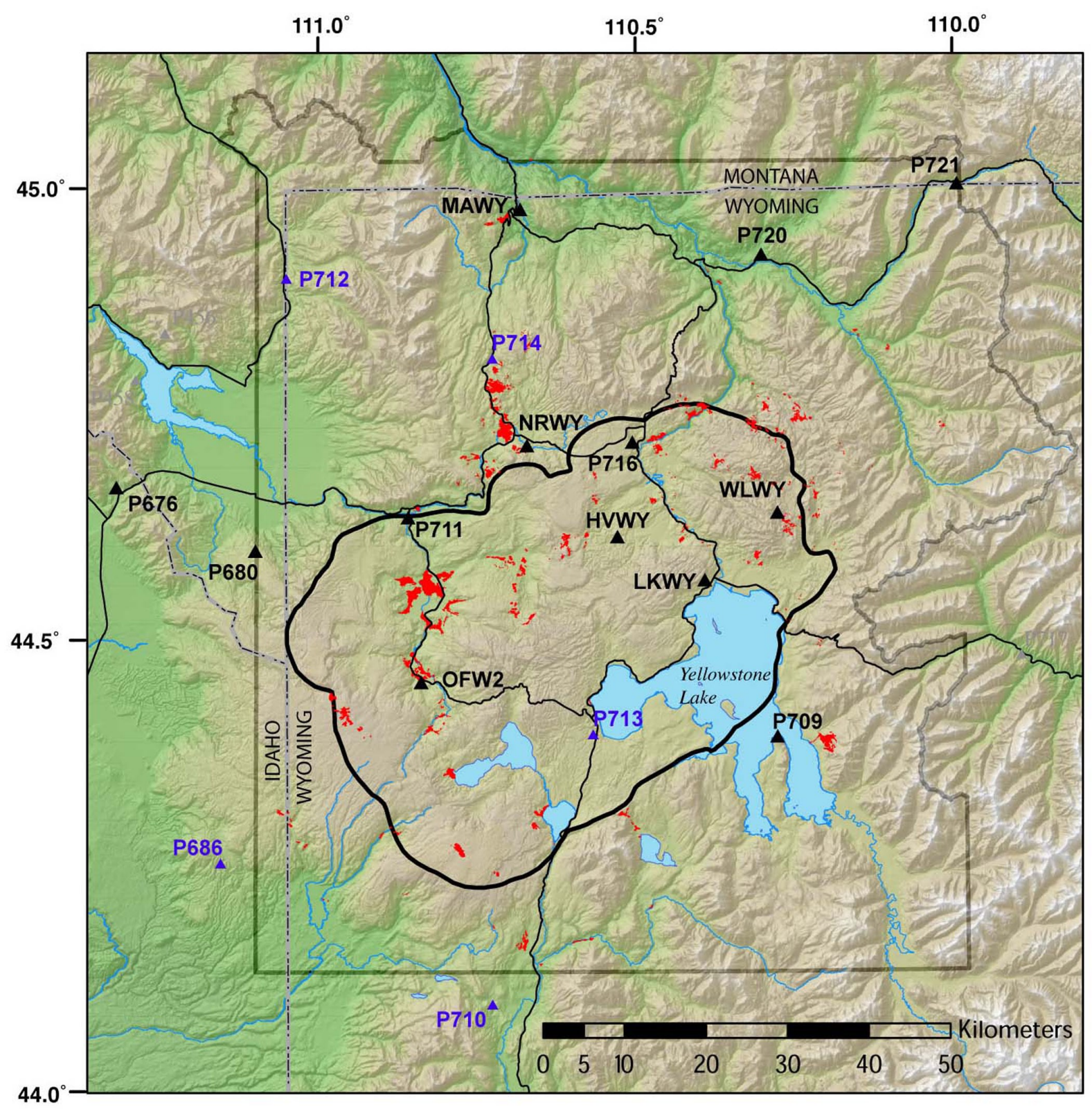

Figure 3. GPS network of Yellowstone National Park. Black triangles and associated letter codes are existing GPS stations. Blue triangles are planned GPS stations. Thick black line is the boundary of the Yellowstone Caldera. Thin black lines are roads. Gray outline is park boundary. Red regions are thermal areas. 
4. Anticipated Future Volcano and Earthquake Monitoring Needs for the Yellowstone Volcanic Field-A 10Year View

In this section we outline proposed additions and upgrades to the YVO "backbone" network, which monitors the entire park through a distributed network (see fig. 5).

\section{4a. Proposed Upgrades to Seismic Network}

1. Upgrade 10 of the single-component seismometers to modern broadband stations. The upgrade would also include accelerometers and telemetry for six channels of data. Such technology would allow YVO to locate earthquakes more precisely and to provide detailed information about local ground movements to emergency responders. The upgraded stations would also enable researchers to better

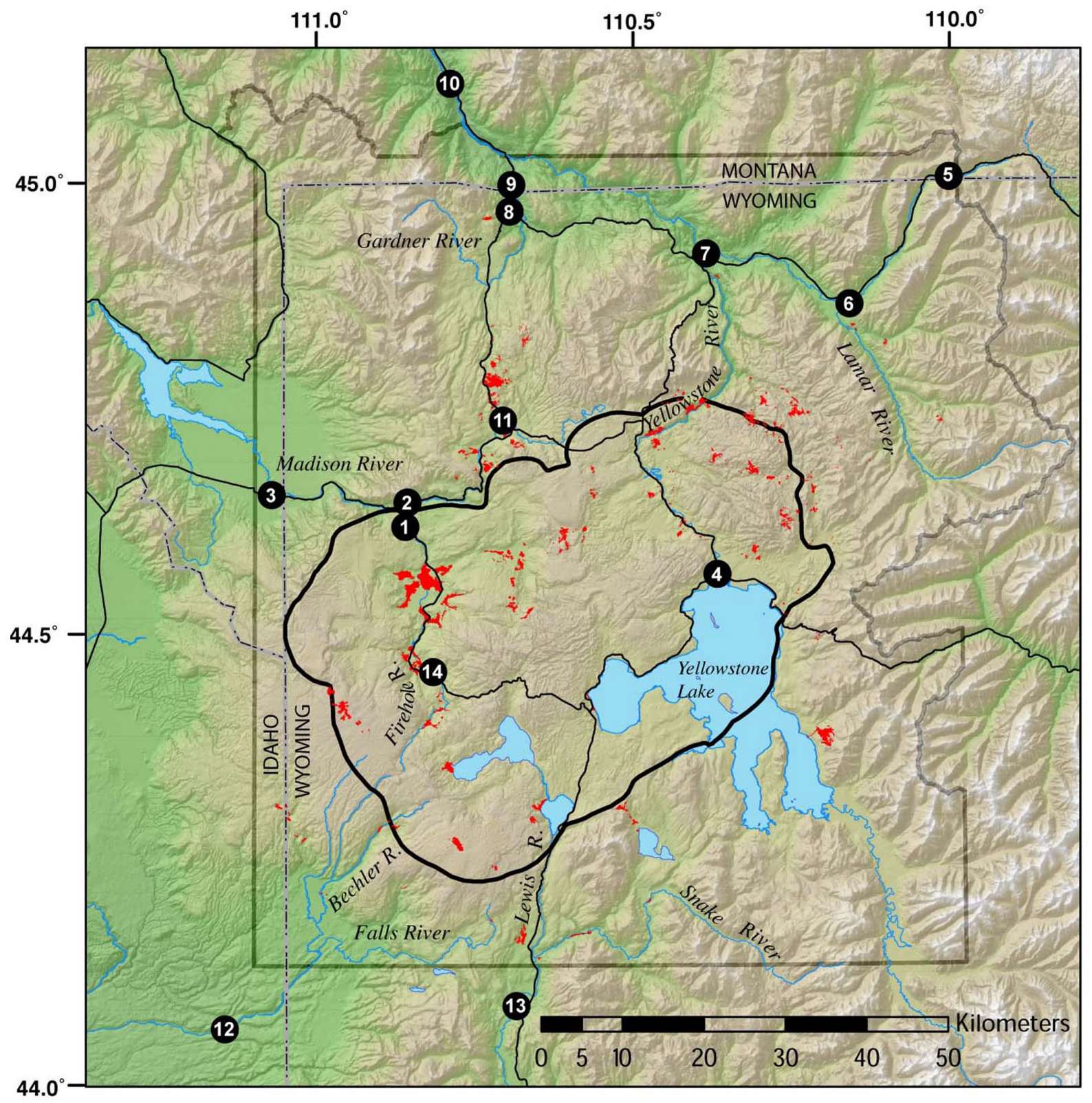

Figure 4. Stream gages of Yellowstone National Park. Numbers correspond to stations in appendix 1. Thick black line is the boundary of the Yellowstone Caldera. Thin black lines are roads. Gray outline is park boundary. Red regions are thermal areas. 
discriminate between tectonic earthquakes and earthquakes that involve significant movements of hydrothermal or magmatic fluid.

2. Add as many as five new seismograph stations to poorly monitored regions within the park. This would permit YVO to locate small earthquakes in remote areas. Currently, earthquakes are preferentially detected in the northwest part of the park because of the greater density of seismic stations in that area (potential sites include Thorofare, East Entrance,
Northeast Entrance, Roaring Mountain, and northern west boundary). Both the East and Northeast Entrance sites were previously occupied by USGS seismic stations.

3. Install five three-component downhole seismometers in coordination with PBO's installation of borehole strainmeters with waterlevel indicators. The high signal-to-noise ratio of downhole instruments will allow YVO to detect seismic signals that may go unnoticed

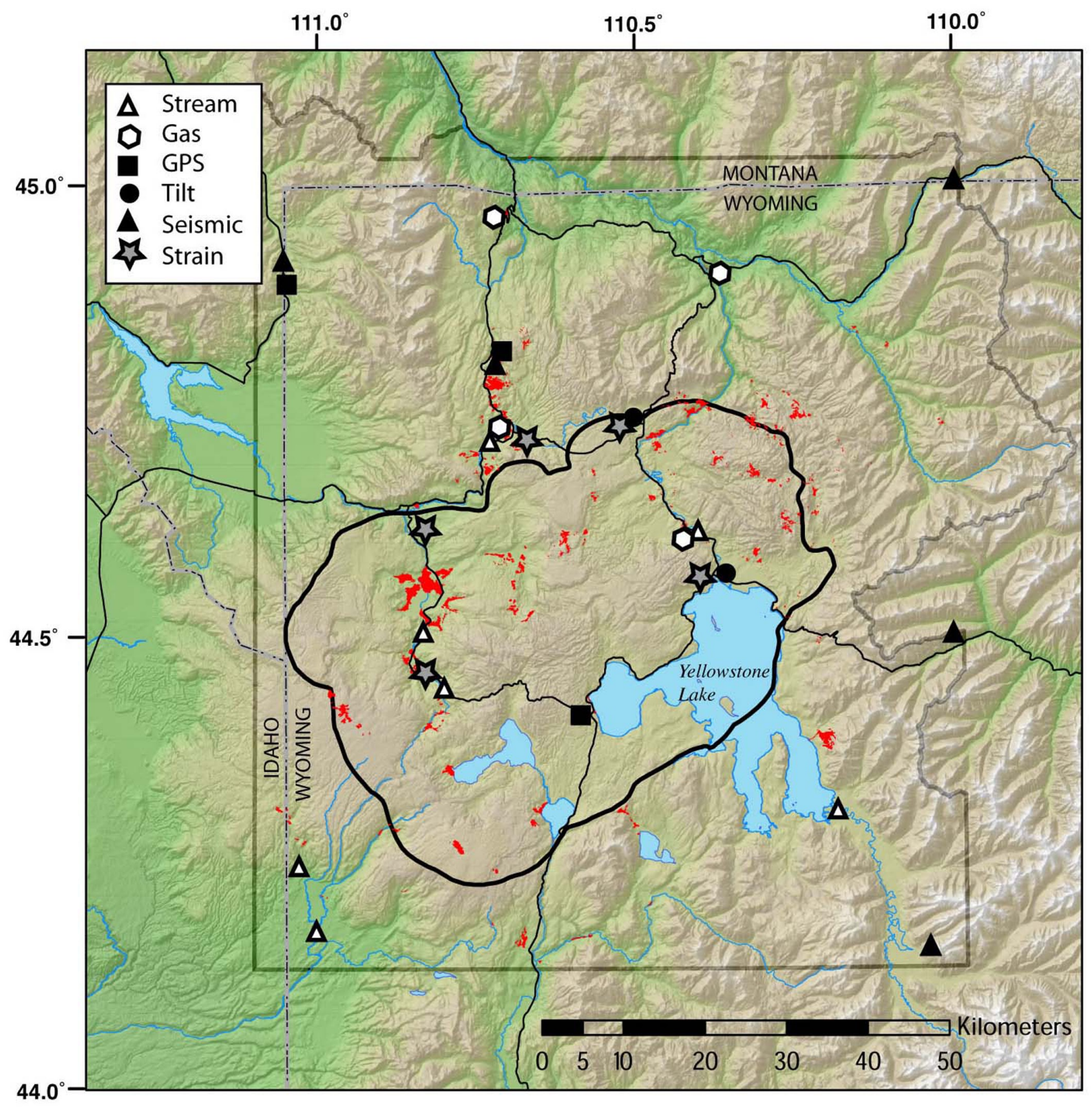

Figure 5. Proposed new instruments to be added to the backbone volcano-monitoring network. See text for details. Thick black line is the boundary of the Yellowstone Caldera. Thin black lines are roads. Gray outline is park boundary. Red regions are thermal areas. 
with the current network. These stations are funded through the NSF but require permitting, as well as installation. Potential sites are in developed areas near Canyon, Norris, Madison Junction, Old Faithful, and Lake.

\section{4b. Proposed Upgrades to Geodetic Network}

1. Coordinate with PBO to install three continuous GPS stations (West Thumb, Roaring Mountain, and northern west boundary) and five borehole strainmeters, colocated with downhole seismometers. The GPS stations are funded through NSF and have been permitted by YNP, but they have not been installed as of May 2006.

2. Add two tiltmeter stations in existing boreholes in developed areas to provide capability of real-time monitoring of ground deformation. Such installations will be especially useful if strainmeter deployment is delayed.

3. Install small (24-inch) radar reflectors at a number of sites within the park above the level of the snow pack, so that InSAR data can be collected during the winter months and compared to previously collected data. This would allow monitoring of ground movement via satellite at many more locations than is possible with the continuous GPS stations. At the present time, this technique is still experimental, but it is possible that within the next few years a series of well-placed radar reflectors could considerably aid the YVO monitoring program. The reflectors can be camouflaged, and they require neither power nor associated telemetry.

\section{4c. Proposed Upgrades to Gas, Water, and Thermal Monitoring Network}

1. Install three or four continuous gas-monitoring stations that measure the concentrations of $\mathrm{H} 2 \mathrm{~S}$ and $\mathrm{CO} 2$ at waist-level in the air near active thermal areas. The data would ideally be telemetered to YVO staff in real time. These stations would serve several purposes. They would allow the park to determine the frequency with which concentrations of $\mathrm{H} 2 \mathrm{~S}$ and $\mathrm{CO} 2$ in the air reach unhealthy levels. They would provide information on relations between climatic factors (air temperature, wind speed, barometric pressure, and precipitation) and gas discharge over long periods. These data also would allow YVO to assess whether pulses of gas are emitted from the Yellowstone hydrothermal system, as opposed to a more continuous discharge.

2. Install three or four $\mathrm{CO} 2$ gas-flux monitoring stations where the rate of gas emission is measured directly.
This would be done with either a flux chamber that periodically pumps $\mathrm{CO} 2$ through the soil into a gas analyzer or a weather station and $\mathrm{CO} 2$-air sensor using eddy covariance techniques to calculate discharge. Compared with the stations proposed in item 1 above, these techniques allow more quantifiable evaluation of gas discharge versus time and are more useful for volcano monitoring.

3. Add new stream gaging stations at the following locations:

Firehole River above Midway Geyser Basin

Gibbon River near Norris

Yellowstone River near Mud Volcano

Yellowstone River south of Yellowstone Lake

Boundary Creek

Bechler River

These stations would collect data on water flow, but also on water and air temperature and precipitation. A few gages would have sensors to collect information on water chemistry, such as conductivity, $\mathrm{pH}$, or selected anions. Theses sensors will allow analysis of the relative input of thermal fluid from different regions into the rivers of Yellowstone and could be used to track anomalous pulses of thermal fluids out of the subsurface.

4. Install at Norris a small network of temperature sensors in thermal pools, stream channels, and soils that is capable of data transmission to a central node. The data relays will permit YVO personnel to recognize when individual sensors are compromised and can prevent weeks or months of lost data. If the data can be transmitted in real time, they can provide insight into new or ongoing thermal events that currently are only recognized in hindsight.

In addition to the upgrades and additions described above, YVO would continue its current campaign of geochemical and thermal monitoring, including (a) annual gas flights with fixed-wing aircraft to calculate the $\mathrm{CO}_{2}$ discharge from geyser basins, (b) ground-based flux measurements with portable instruments, (c) geochemical sampling of water and gases from selected features, (d) annual infrared monitoring flights to detect long-term growth or shrinkage of thermal areas and (e) periodic reconnaissance of sub-lake-floor vent systems.

\section{4d. Data Transfer and Archiving}

Most of the monitoring efforts proposed above will require real-time data transmission through FM radio, wi-fi, cellular, or satellite technologies. Combined with intelligent 
database systems, the data can be queried through the Internet by scientists, resource managers, emergency responders, and the general public. Without such technology, YVO will be unable to add new monitoring techniques or additional stations.

Currently, the YVO monitoring infrastructure is highly vulnerable to loss of data-transmission capabilities. For example, an earthquake affecting the integrity of the Mt. Washburn relays could cause YVO to lose 75 percent of its seismic and GPS data, resulting in loss of information on the nature of the event and any potential aftermath scenarios. Public safety at Yellowstone will best be ensured if YVO can build a robust data-transmission system, allowing multiple pathways for data out of the park. Potentially, satellite, radio, and wireless systems could all be used and so provide sufficient flexibility that data loss could be minimized during natural and man-made disasters. YVO needs to work with YNP, UUSS, the Department of the Interior, and private interests to create a secure, efficient and reliable data-delivery system.

\section{4e. Nonpermanent Monitoring (Temporary Experiments)}

The proposed permanent upgrades listed above will provide a more robust and reliable backbone for geophysical and geochemical monitoring of the Yellowstone system. However, much can also be learned from temporary deployments of dense, portable networks installed in key locations such as the Norris Geyser basin or the Firehole River basins. Such deployments could include any combination of seismometers, GPS stations, tiltmeters, temperature loggers, gas sensors, or other instrumentation. Experiments could last as little as a day or as much as a few months. The equipment can be installed with negligible visual impact and can be completely removed when the experiment is finished. We envision that many of the breakthroughs for understanding the Yellowstone magmatic and hydrothermal system may come from these short experimental deployments, done in concert with the backbone monitoring system. They may be especially useful for understanding short-term changes to thermal areas, precursors to hydrothermal explosions, or the links between earthquakes and disruption of hydrothermal activity.

\section{Monitoring for Hydrothermal Explosions}

\section{5a. Introduction}

Other than earthquakes and landslides, hydrothermal explosions are the most prominent geologic hazard at Yellowstone that threatens park infrastructure and visitor safety. At least 20 large (>100 meters) craters owe their origin to catastrophic explosions of Yellowstone's shallow boiling groundwater system during the past 15,000 years. It is estimated that small rock-hurling explosions occur somewhere in the park almost every year. Most are not reported or go unnoticed for years because they occur in backcountry settings. Others have been described in some detail (for example, explosions at the Excelsior, Porkchop, Black Opal, Semicentennial, Sapphire, and Echinus thermal features). Park visitors may be injured if they are present when Yellowstone's thermal features begin to erupt explosively, and park infrastructure can be destroyed.

A variety of mechanisms have been proposed for hydrothermal explosions, including triggering by earthquakes, fluctuations in ground-water pressure due to climatic factors, thermal/pressure pulses arriving from depth, or a buildup of gas pressures. Whatever their cause, the responsible variables can be measured and may provide clear indications of increased instability of the geothermal system. Unfortunately, YVO's regional (backbone) monitoring system is unlikely to detect localized precursors to hydrothermal explosions except at individual stations. A small local network of seismic stations and ground-deformation stations, combined with thermal and chemical monitoring, might provide sufficient data to provide warnings of upcoming hydrothermal explosions. Deployment of simple pressure and temperature sensors in existing ground-water wells could also be highly useful. Temperature increases were noted before the 1989 explosion of Porkchop Geyser, and real-time thermal monitoring might provide critical information about such local instabilities. Although there is no guarantee that any monitoring system could predict a hydrothermal explosion, the data provided after the explosion would almost certainly allow us to ascertain the conditions that contributed to the explosive event. Until Yellowstone's thermal areas are instrumented at a basic level, we shall remain unaware of the conditions leading to hydrothermal explosions.

\section{5b. Proposed Instrumentation for a Hydrothermal Monitoring Network}

1. Add a network of at least three GPS stations in one or two selected thermal areas, such as Norris (fig. 6) and the Upper Geyser Basin, to assess the potential for detecting precursors to hydrothermal explosions and to determine the interdependence between regional deformation and hydrothermal activity. In the same area(s), add a network of at least three seismic stations to assess the potential for detecting precursory seismic signals to hydrothermal explosions and to determine the interdependence between regional earthquakes and hydrothermal activity.

2. Add a local temperature-sensor network (potentially the one proposed above in section $4 \mathrm{c}$, item 4) to detect anomalous temperature increases in ground and water temperatures).

3. Add three new gas-flux measuring stations to assess changes in gas discharge related to disturbances, regional deformation, or hydrothermal explosions.

4. Add instrumentation in existing shallow wells to detect changes in the pressure and temperature of the local ground water (not shown in fig. 6). 
5. Add two or three shallow tiltmeters to provide real-time indicators of crustal strain (not shown in fig. 6).

The above list outlines a skeletal monitoring system for a hydrothermal basin. No such network exists in the world today, and it is virtually certain that it would provide unequalled opportunities to determine the interactions between geothermal activity (ground-water flow, boiling, mineral reactions), regional tectonism (earthquakes and crustal strain), and magmatic processes (intrusion and gas discharge). Besides the scientific insights, it would offer a real hope of measuring and understanding precursory phenomena to hydrothermal explosions.

\section{Summary}

This plan outlines a series of steps for YVO to build and operate a reliable volcano and earthquake monitoring system that meets the expectations of society for public safety and allows for improved understanding of the Yellowstone volcano. It also recognizes the need to tread lightly on the Yellowstone ecosystem, minimizing new monitoring sites and keeping all others as unobtrusive as possible. By deploying innovative yet unobtrusive instrumentation, YVO strives to protect the public while educating it about Yellowstone's active volcanic environment. YVO aims to meet the diverse needs of land and city managers, park visitors, scientists, and society.

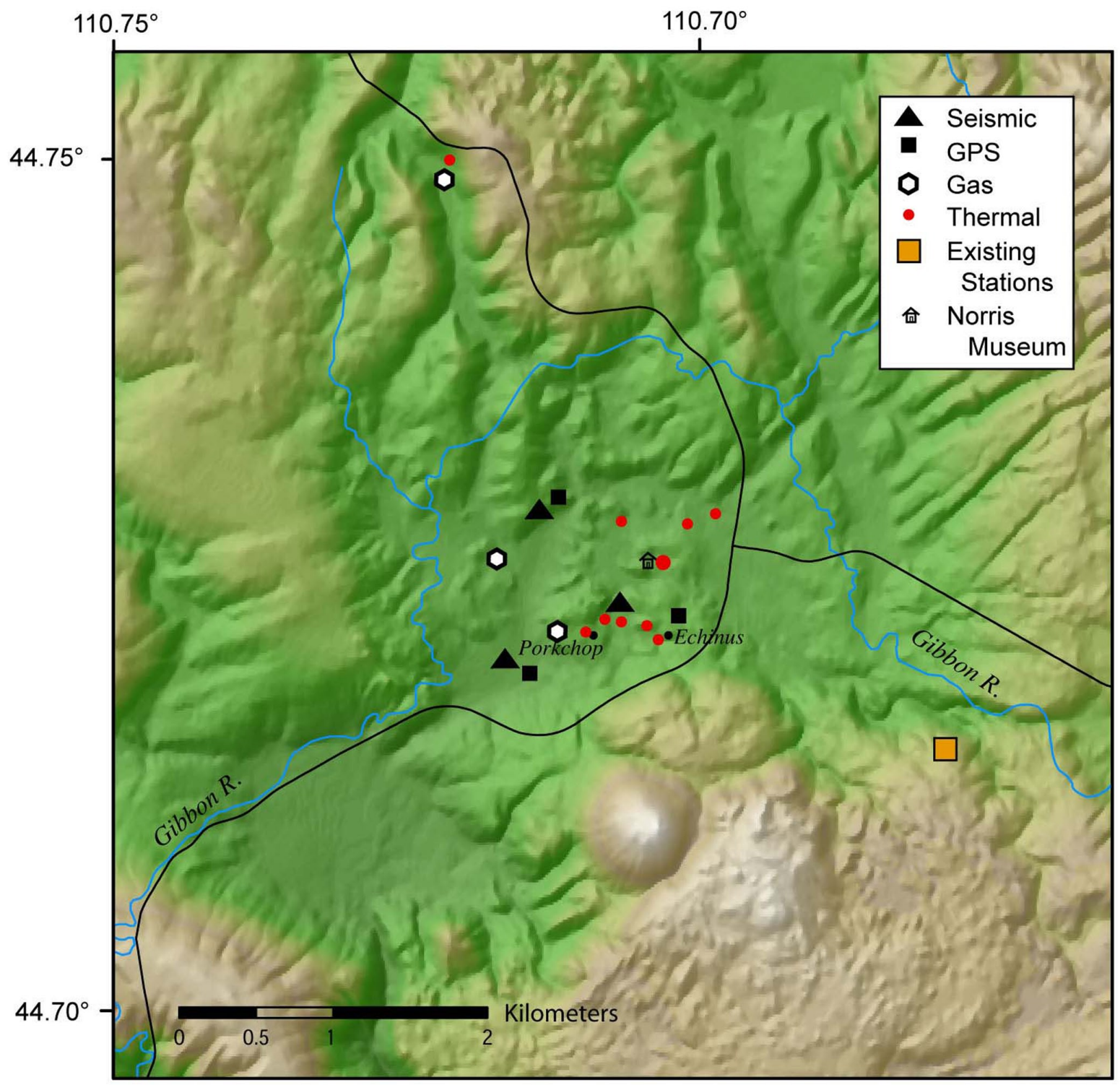

Figure 6. Potential hydrothermal monitoring network for Norris Geyser Basin. The larger red dot by the Norris Museum is a base station for the thermal (temperature-logger) network. Thin black lines are roads. Small black dots are place-names. 


\section{Appendix 1. Locations and Names of Monitoring Stations}

\begin{tabular}{|c|c|c|c|}
\hline Symbol & Name, Location & Lat & Lon \\
\hline Seismic & Stations (DATUM: WGS84) & & \\
\hline FLWY & Flagg Ranch & 44.0830 & 110.6990 \\
\hline LKWY & Yellowstone Lake & 44.5652 & 110.4000 \\
\hline MCID & Moose Creek ID & 44.1908 & 111.1838 \\
\hline YDC & Denny Creek & 44.7090 & 111.2400 \\
\hline YFT & Old Faithful & 44.4500 & 110.8360 \\
\hline YGC & Grayling Creek & 44.7960 & 111.1070 \\
\hline YHB & Horse Butte & 44.7500 & 111.1920 \\
\hline YHH & Holmes Hill & 44.7880 & 110.8510 \\
\hline YJC & Josephs Coat & 44.7600 & 110.3490 \\
\hline YLA & Lake Butte & 44.5130 & 110.2690 \\
\hline YLT & Little Thumb Creek & 44.4370 & 110.5870 \\
\hline YMC & Maple Creek & 44.7590 & 111.0060 \\
\hline YML & Mary Lake & 44.6050 & 110.6430 \\
\hline YMP & Mirror Plateau & 44.7400 & 110.1560 \\
\hline YMR & Madison River & 44.6690 & 110.9630 \\
\hline YMS & Mt. Sheridan & 44.2640 & 110.5280 \\
\hline YMV & Mammoth Vault & 44.9740 & 110.6890 \\
\hline YNR & Norris & 44.7160 & 110.6790 \\
\hline YPC & Pelican Cone & 44.6470 & 110.1920 \\
\hline YPK & Parker Peak & 44.7318 & 109.9214 \\
\hline YPM & Purple Mountain & 44.6570 & 110.8670 \\
\hline YPP & Pitchstone Plateau & 44.2667 & 110.8000 \\
\hline YSB & Soda Butte & 44.8840 & 110.1510 \\
\hline YTP & The Promontory & 44.3920 & 110.2850 \\
\hline YUF & Upper Falls & 44.7126 & 110.5118 \\
\hline YWB & West Boundary & 44.6060 & 111.1010 \\
\hline GPS & Stations (DATUM: WGS84) & & \\
\hline HVWY & Hayden Valley & 44.6137 & 110.5358 \\
\hline LKWY & Lake Yellowstone & 44.5651 & 110.4002 \\
\hline MAWY & Mammoth Hot Springs & 44.9770 & 110.6850 \\
\hline NRWY & Norris & 44.7155 & 110.6792 \\
\hline OFWY2 & Old Faithful & 44.4525 & 110.8413 \\
\hline P680 & West Yellowstone & 44.5984 & 111.0987 \\
\hline P709 & Promontory & 44.3914 & 110.2892 \\
\hline P711 & Madison Junction & 44.6356 & 110.8611 \\
\hline P716 & Canyon & 44.7183 & 110.5116 \\
\hline P720 & Slough Creek & 44.9259 & 110.3089 \\
\hline P721 & NE Entrance & 45.0030 & 110.0021 \\
\hline WLWY & White Lake & 44.6395 & 110.2866 \\
\hline
\end{tabular}




\section{Stream Gages (DATUM: NAD27)}

1 Firehole River near West Yellowstone, MT

44.6202

110.8630

2 Gibbon River at Madison Jct

44.6405

110.8610

3 Madison River near West Yellowstone, MT

44.6569

111.0683

4 Yellowstone River at Yellowstone Lake Outlet

44.5674

110.3808

5 Soda Butte Creek at Park Boundary at Silver Gate

45.0030

110.0019

6 Soda Butte Creek near Lamar Ranger Station, YNP

44.8683

110.1655

7 Lamar River near Tower Falls Ranger Station, YNP

44.9277

110.3938

8 Boiling River at Mammoth

44.9849

110.6891

9 Gardner River near Mammoth, YNP

44.9924

110.6913

10 Yellowstone River at Corwin Springs

45.1119

110.7944

11 Tantalus Creek at Norris Junction, YNP

44.7330

110.7150

12 Falls River above Yellowstone Canal near Squirrel, ID

44.0630

111.1461

13 Snake River above Jackson Lake at Flagg Ranch, WY

44.0891

110.6947

14 Firehole River at Old Faithful, YNP 